\title{
Profiles in Cardiology
}

This section edited by J. Willis Hurst, M.D., and W. Bruce Fye, M.D., M.A.

\section{Joseph Skoda}

\author{
ZDENĚK FEJFAR, M.D., AND LUDMILA HLAVAČKOVA, PH.D. \\ Institute for the History of Medicine, First Medical Faculty, Charles University Prague, Prague, Czech Republic
}

Joseph Skoda was born in Plzeñ, Czechoslovakia, on May 12,1805 . The third son of a poor locksmith, he had to give private lessons as a teenager in order to graduate from the gymnasium (high school) in Plzeñ. There was no money for candles or lamp oil, and the adolescent Skoda spent evenings studying by the light from the kitchen stove flames. In 1825 , after graduation and studies in philosophy, he went to Vienna to study medicine. In addition to medicine he studied higher mathematics and physics and he passed the examination so successfully that his teacher, Prof. Baumgartner, urged him to devote his life to mathematics.

The degree of doctor of medicine was conferred on Skoda on July 18,1831 . Because of the cholera epidemic at that time he was obliged, as were other doctors, to work in the so-called cholera districts. Young Skoda, with a fresh medical degree, performed this duty for a year, leaving it in November 1833. On his return, he obtained a job at Vienna General Hospital as a houseman without pay. This started his amazing career as the founding father of modern physical diagnostics. His famous courses on diseases of the chest began in 1834 and soon attracted young colleagues from the Austrian monarchy as well as from other European countries. ${ }^{1}$

Objective observation based on physical diagnosis confirmed or corrected by pathology revolutionized medicine at that time-the generation before Skoda and his friend Rokitansky had attempted to explain diseases by changes in the environment (temperature, barometric pressure, humidity, etc.). Percussion of the chest, introduced by the Austrian L. Auenbrugger in his book, published in 1771 in Latin, remain-

Address for reprints:

Prof. MUDr. Zdenek Fejfar, Dr. Sc.

Menšíkovská 18

16000 Praha 6

Czech Republic

Received: April 28, 1997

Accepted: April 28, 1997 ed unnoticed in his country. It was promoted, on the other hand, by J.N. Corvisart (1755-1821) in Paris, and together with auscultation, introduced by R.T.H. Laennec (17481822), the French clinicians moved ahead of the old Austrian school. Their diagnostic conclusions, however, were reached intuitively, and percussion or auscultation phenomena were ascribed as typical for specified organ disease (liver, lung tuberculosis, etc.).

Skoda reimported Auenbrugger's use of percussion. His approach —in contrast to that of the French colleagues- was based solely on the objective description of physical signs. To him, the acoustic phenomena produced by percussion were not specific for a given organ, but for the amount of air or fluid; hollow, empty, tympanic, high, deep, clear, dull. Based on acoustic phenomena, Skoda tried to explain the physical changes in an organ and then, from the anatomical and pathologic possibilities, he reached a clinical diagnostic conclusion.

In a similar way, Skoda developed a system of physical diagnosis of the diseases of the heart and pericardium. His classical monograph Abhandlung über Percussion und Auscultation was first published in $1839 .{ }^{2}$

Although he was famous abroad and well-known in European intellectual circles, he was not accepted--was even rejected - by older Austrian doctors who could not understand his new diagnostic procedures. Before instituting a new procedure at the Vienna General Hospital, it was necessary to obtain the approval of the director and the chief physician of the hospital. In their absence and thus without their consent, Skoda performed a tracheotomy with his colleague, surgeon Schuh. The procedure was performed correctly; nevertheless, Skoda was in danger of losing his medical license. Fortunately, thanks to his fame, which was recognized in Austria by, among others, the Court Councellor baronet Türckheim, officer in charge of the Court Committee for Studies, Skoda was disciplined only by having to work in an asylum for three months.

Skoda's chief in the medical department allowed him, however, to continue his diagnostic investigations. Nevertheless, Skoda declined to prolong his contract with the Vienna General Hospital that year and, in October 1839, started work as doctor of the poor in St. Ulrich, a suburb of Vienna. The temporary assignment did not stop his increasing fame. 


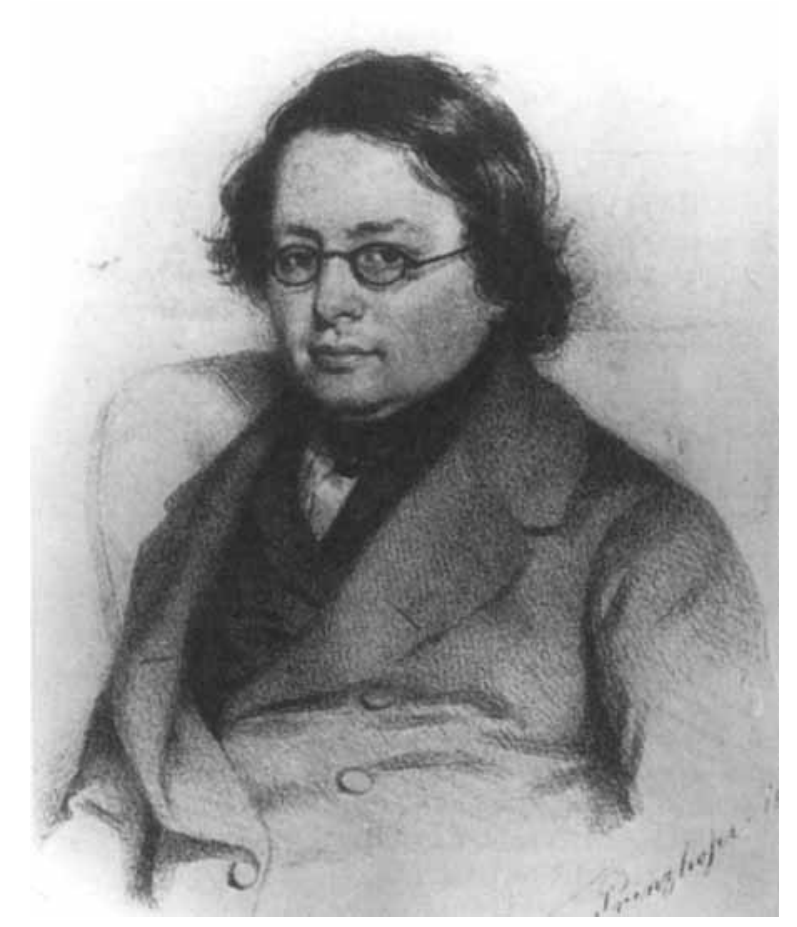

FIG. 1 Joseph Skoda (1805-1881). Reproduced by permission of the Institute for the History of Medicine, University of Vienna, Vienna, Austria.

The case of the Duc de Blacas, a resident of Vienna, is an example of Skoda's expertise. Three top Austrian experts diagnosed the severe state of health of the patient as liver disease. The duke's French personal physician was not in agreement with them and asked for a consultation with Dr. Skoda. The latter, using his technique of percussion and auscultation, found a large abdominal aneurysm and predicted an early death of the patient. At autopsy, Skoda, using percussion, again proved that he had outlined the dimensions of the aneurysm correctly.

One of the consultants was Dr. Türckheim, who realized the importance of the new diagnostic approach and followed all of Skoda's activities (e.g., pericardial paracentesis, performed again with Dr. Schuh 1840). He also appreciated the fact that an increasing number of foreign doctors came to Vienna to learn Skoda's diagnostic methods. In 1840, he established the department for diseases of the chest, with Skoda in charge. A year later, Skoda was appointed chief physician and the department was expanded to include two wards, for internal and skin diseases. Skoda selected young Dr. F. Hebra from Moravia (1816-1880) to care for patients with skin diseases. The choice was excellent; in a few years, Hebra became another leading physician of Czech origin at the Vienna University and is considered the founding father of classical dermatology.

In September 1846, Skoda was at last given the chair of Professor of Special Pathology and Therapy at the Vienna
University and became Ordinarius at the Department of Internal Medicine. Two years later, he became a full member of the Royal Academy of Sciences in Vienna. For reasons of health (he suffered from severe gout for years) Prof. Skoda resigned from all his functions in 1871. The students honored him with a famous torch parade. He died in Vienna 10 years later and was buried in the same cemetery as Hebra and Rokitansky. The three stars of the Vienna second medical school remain together for eternity. ${ }^{3}$

The most famous publication by Skoda was Percussion and Auscultation (1st edition 1839), in which the young house physician described the fundamentals of physical diagnostics that are still valid today. In the same year, jointly with the pathologist J. Kolletschka (1803-1847), he published an important paper on the relation between the pathology and inlife diagnosis of pericarditis. The authors presented precise observations in patients and compared them with autopsy results in a way never done before. Diagnosis of the pericardial concrescence in life is the subject of another important paper that utilizes the physiologic approach to describe the influence of the atria and of lung ventilation on function of the heart and on circulation. 4,5

Skoda critically evaluated various therapeutic approaches using statistical methods and tried to eliminate those that were ineffective, futile, or harmful (e.g., ungrounded venesection). On the other hand, he treated patients with digitalis, quinine and scilla (squill), started to use chloralhydrate, salicylates, and syringe of Pravaz. The label of "therapeutic nihilist" conferred on him by some of his pupils was unjustified and unjust. Moreover, he insisted on prophylactic hygienic measures (for example, of the drainage and water supply in Vienna) in view of the epidemics of cholera and typhoid, and supported the effort of I.F. Semmelweiss. ${ }^{1}$

Dr. Joseph Skoda died June 13, 1881. He ended his life as a famous and wealthy physician but used the greater part of his possessions for charity and also for financial support of his cousin in Plzeñ, the founder of the Skoda automobile factory.

\section{References}

1. Lesky E: Wiener medizinische Schule im 19. Jahrhundert, p. 1660. Graz, Cologne, Vienna: Herrmann Böhlauf, 1865

2. Škoda J: Abhandlung über Perkussion und Auskultation, p. 1-27I. Vienna: I.G.Ritter von Mösle Witwe \& Braumüller, 1839

3. von Schrötter L: Josef Skoda. Wiener klin Wschrft 1805;18(50): $1-26$

4. ŠKoda J: Erscheinungen, aus denen sich die Verwachsung des Herzens mit dem Herzbeutel am lebenden Menschen erkennen lässt. Reprint of the Royal Academy of Sciences (mathematics-natural history class) session, November 1851

5. Skoda J: Über die Funktion der Vorkammern des Herzens und über den Einfluss der Contractionskraft der Lunge und der Respirationsbewegungen auf die Blutzirkulation. Reprint of the Royal Academy of Sciences (mathematics-natural history class) session, November 1852 